\title{
Relative Clauses in Magahi- A Descriptive Story ${ }^{i}$
}

\author{
Lata Atreya $^{1}$, Rajesh Kumar $^{2}$ and Smriti Singh ${ }^{3}$
}

\section{Introduction}

The paper aims at describing relative clauses in Magahi. Magahi is an Indo-Aryan language spoken mainly in Bihar and Jharkhand. It is also spoken in some district of Bengal and Orissa. Magahi has SOV wordorder along with scrambling. The canonical word-order of Magahi is S-IO-DO-V. Magahi exhibits postpositions. Verb and subject in Magahi exhibit agreement only for person feature and not for number or gender feature. There is agreement also for honorificity. In Magahi, there is also agreement for number and gender feature between noun and adjective.

Relative clause is one of the major aspects to understand the syntax of a language. Relative clauses are sentences embedded to modify a noun. Subbarao (2012) writes "A relative clause is a clause that modifies a phrasal constituent, generally a noun phrase. We call the noun phrase so modified the head of the relative clause (Reimsdijk 2006: 338)." He adds "A relative clause is a subordinate clause in which the embedded predicate may be [+Finite] or [- Finite]." Relative clause can be categorised into different categories. Relative clause can be sentential relative clauses (SRC) or participial relative clauses (PRC). They can be restrictive or nonrestrictive relative clauses. Relative clause can also be categorised as externally headed relative clause (EHRC) and internally headed relative clause (IHRC). There is a special kind of relative clauses known as correlatives "in which a special lexemic pair is used to link the relative NP with its corresponding head NP" (Wali 2011).

The description of relative clause in this paper follows Comrie and Smith (1977). There is a review of description of relative clauses in other Indo-Aryan languages: Maithili, Marathi and Punjabi. There is a comparison of description of relative in Magahi with that of Maithili, Marathi and Punjabi. The description starts with the classification of relative clauses with illustration exclusively from Magahi.

\section{Classifications}

Relative clauses can be classified into following categories:

a) Sentential relative clauses (SRC) and participial relative clauses (PRC)

b) Restrictive and non-restrictive clauses

c) Externally headed relative clause (EHRC), Internally headed relative clauses (IHRC) and Correlatives The classification SRC and PRC are based on finiteness of the verb in relative clause. An example of SRC is illustrated in (1), while that of PRC is illustrated in (2). The classification of relative clauses as restrictive and non-restrictive clause is based on the nature of the head modified. "SRC are usually restrictive, except those with proper nouns as their heads in other words they become non-restrictive clause as illustrated in (3). PRC in general are ambiguous between the restrictive and non-restrictive interpretation except in those cases when head noun is either a proper noun or a definite noun phrase...(Pandharipande, 1997)." A sentence of PRC which is ambiguous between restrictive and non-restrictive is illustrated in (4).
(1) je $\quad c^{\mathrm{h}}$ auraa
rel boy
dauR hai se hamar
$b^{h}$ aai hai

'The boy who runs is my brother.'

(2) daurat $\mathrm{c}^{\mathrm{h}}$ oraa hamar $\mathrm{b}^{\mathrm{h}}$ ai hai

running boy mine brother is

'Running boy is my brother.'

\footnotetext{
${ }^{1}$ Research Scholar in the Department of Humanities and Social Sciences at the IIT Patna

${ }^{2}$ Teaches in Department of Humanities and Social Sciences at the IIT Madras

${ }^{3}$ Teaches in Department of Humanities and Social Sciences at the IIT Patna
} 
$\begin{array}{llllll}\text { (3) rosy } & \text { jekar } & \text { kitaab } & \mathrm{c}^{\mathrm{h}} \text { aple hai } & \text { hamar bahin hai } \\ \text { rosy } & \text { rel } & \text { book } & \text { publish is } & \text { my } & \text { sister is }\end{array}$

'Rosy whose book is published is my sister.'

$\begin{array}{llll}\text { (4) } \text { pad }^{\mathrm{h}} \text { ait } & \mathrm{c}^{\mathrm{h}} \text { oraa } & \text { hamraa se } & \text { puc }{ }^{\mathrm{h}} \text { alkai... } \\ \text { study-PPL } & \text { boy } & \text { me } & \text { ABL asked... }\end{array}$

'The boy who was studying asked me...'

The classification of relative clauses as EHRC, IHRC and correlatives is based on the position of head noun in the matrix clause. Subbarao (2012) writes "In EHRC the head is overtly present in the matrix clause. In these categories there are two subtypes. The relative clause may be finite or non-finite (infinitival or participial) and the latter may be pre-nominal and post-nominal which is language specific." He further adds "In subtype 1, the relative clause is sentential relative clause in which the embedded relative clause occurs to the right of the head noun phrase or of the VP of the matrix clause. The embedded verb is [+Finite]. In subtype 2 the embedded verb is [-finite]." EHRC may be right adjoined as illustrated in (5), left adjoined as illustrated in (6) or embedded as illustrated in (7).

$\begin{array}{llllll}\text { (5) uu } & \text { kotvaa hamar hai } & \text { je } & \text { kaar hai } \\ \text { rel } & \text { coat } & \text { mine } & \text { is } & \text { rel } & \text { black is }\end{array}$ 'The coat which is black is mine.'

$\begin{array}{llllll}\text { (6) je } & \text { kaar } & \text { hai } & \text { uu } & \text { koTvaa } & \text { hamar hai } \\ \text { rel } & \text { black } & \text { is } & \text { corr } & \text { coat } & \text { mine is }\end{array}$ 'The coat which is black is mine.'

$\begin{array}{llllll}\text { (7) uu } & \text { koTvaa } & \text { je } & \text { kaar hai } & \text { se hamar hai } \\ \text { corr } & \text { coat } & \text { rel } & \text { black is } & \text { corr mine is }\end{array}$ 'The coat which is black is mine.'

IHRCs do not exist in Indo Aryan languages. However, head occurs internal to the left adjoined relative clauses as illustrated in sentence (8). The characteristics of IHRC are that head occurs inside the embedded relative clause and the embedded verb is infinitival (nominalized) (Subbarao 2012).

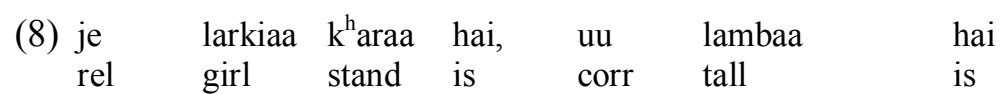
"The girl who is standing is tall.'

The above illustration (8) is a left adjoined relative clause as the relative phrase je larkiaa $k^{h}$ araa hai is on the left periphery of the sentence. This relative phrase has head NP larkiaa internal to it, but is not an illustration of IHRC as it does not fulfil the criteria of IHRC mentioned above.

On correlatives, Subbarao (2012) writes "In this pattern a Demonstrative Phrase in the matrix clause is coindexed with the relativized noun phrase in the embedded relative clause." He quotes Bhatt (2003) on HindiUrdu correlatives and writes "there is a correlative clause that contains a relative phrase... The correlative clause is associated with a matrix clause that contains a demonstrative Phrase."

Following sentence (9) illustrates correlative clause in Magahi.

(9) $\mathrm{uu}$ koTvaa hamar hai je kaar hai

'That coat is mine which is black.'

III. Relative Clauses: A Review

In this section there is a review of the literature on the description of relative clauses in three IndoAryan languages; Marathi (Pandharipande 1997), Punjabi (Bhatia 1993) and Maithili (Yadav 1996).

There exist two kinds of relative clauses in both Marathi and Punjabi. They are sentential relative clauses (henceforth SRC) and participial relative clauses (henceforth PRC). According to Pandharipande (1997), in Marathi both type of relative clauses are equally acceptable but frequency of PRC is higher in both written and spoken language. In Punjabi, Bhatia (1993) opines that finite relative clauses or SRC are known as 'real' relative clause. In Marathi, SRC is marked by relative marker $d z o$ 'who/which' and correlative marker to or asaa (masculine singular) and its variants. PRC is formed by deleting the relativized noun phrase and by 
converting the verb into its participial form. Relative markers in Punjabi are jo 'who/which', correlative marker $o$ and by optionally deleting co referential NP. PRC in Punjabi is formed by the same manner as in Marathi. Both in Marathi and Punjabi finite relative clauses are restrictive except those which have proper nouns as heads. Relative clauses with proper noun heads are called non-restrictive or appositive relative clauses. Participial relative clauses are generally ambiguous between restrictive and non-restrictive clauses. Pandharipande (1997) and Bhatia (1993) observe respectively about Marathi and Punjabi that relative clause may either precede or follow the head noun. Non-restrictive finite clauses follow the head noun while restrictive relative clauses precede the head noun. Participial relative clauses generally precede the head noun. In Punjabi, Bhatia (1993) writes that relativized element is fully expressed when the relative clause precedes the main clause otherwise it is deleted. It is pronominalized when head is a pronoun. Maithili relative clauses are classified by Yadav (1996) into two categories, one is restrictive relative clauses and another is non-restrictive relative clauses. Yadav writes "A relative clause in Maithili is formed by the use of a relativizer, which is the relative pronoun $j e$ and its inflected form." Restrictive relative clauses in Maithili can be postnominal, prenominal or internal which is based on the relative position of head NP in comparison with the relative clause. Yadav gives the word order of postnominal relative clause as "determiner + head + relative clause". The word order of pronominal relative clause is "relative clause + determiner + head". About internal relative clauses, Yadav writes "In an internal relative clause (traditionally known as relative- correlative) the head NP occurs inside the relative clause. The main clause too may have the head NP repeated in it, in which case the head NP is preceded by the correlative-demostrative-determiner; usually, however, the head NP is deleted and only a correlative-demonstrative-third person pronoun is used". Yadav further writes that in Maithili there exists a fourth type of relative clauses called "extranominal relative clauses". Such type of relative clauses are characterised with the head NP containing an indefinite determiner.

In Marathi, in SRC the relativized element may undergo deletion or occur twice, both in main and relative clause. In the PRC, the relativized NP is always deleted. In both Marathi and Punjabi SRC, relative clause may be used clause initially for focus purpose.

Both in Marathi and Punjabi any constituent of the main clause, except verb can be relativized in a finite (sentential) relative clause. In Punjabi, PRC allows the relativization of subject and direct object but not of indirect object. However, in Marathi, except object of postposition, any constituent can be relativized by PRC. When we consider relativization of noun phrases in Marathi, Pandharipande (1997) writes that by using SRC both possessor and possessed noun phrases can be relativized. However in PRC only possessed noun phrases can be relativized. In Punjabi, in finite relative clauses, modifiers and possessors in noun phrases can be relativized along with any constituent of a relative clause.

\section{Relative Clauses in Magahi: A Description}

Based on the finiteness of the verb, relative clauses in Magahi can be categorized as sentential relative clause (SRC) and participial relative clause (PRC). In SRC, finite form of the verb is used with subject-verb agreement for the person feature. As in Magahi, subject agrees with verb only in Person feature and not for Number or Gender feature. PRC uses non-finite form of verb. Unlike Marathi where PRC is more frequent in both written and spoken language, in Magahi, SRC is more frequent in use. In following sections I talk about the constitution of sentential relative clauses (subsection 4.1) and participial relative clauses (subsection 4.2). In subsection $4.3 \mathrm{I}$ talk about restrictive and non-restrictive relative clauses in Magahi. This section follows subsection 4.4 which deals with position of head noun in relative clauses in Magahi. The next section 4.5 deals with position of relativized element in Magahi. Section 4.6 deals with headless relative clauses in Magahi. This follows section 4.7 which deals with Noun Phrases that can be relativized in Magahi. Subsection 4.8 deals with Multi-head correlatives in Magahi.

\subsection{Marking of Finite or Sentential Relative Clause (SRC)}

In Magahi, SRC uses both relative marker and correlative marker. Relative marker is je 'who/which' (direct) and jekaraa or jaun (oblique). Oblique form of relative marker is used when a case marker is used with any lexicon. This can be illustrated with following examples:

(10) a. jaun laRkaawaa ke (ACC)

REL boy ACC

'The boy to whom'

b. jaun laRkaawaa se (INST)

c. jaun Tebulwaa par (LOC)

From the above illustration (10), we find that the oblique form jaun is used with the lexeme laRkaawaa, when the lexeme is followed by Case marker like ke 'ACC', se 'INST' or par 'LOC'. Details of use of oblique form of relative marker and its relation with Case marker in Magahi are available in work by Chandra (2013). 
Correlative marker in Magahi is se (direct) and sekraa (oblique form which is used only in reduplication with jekraa). There is a correlative pronoun in Magahi which is $u u$ (direct) and okraa (oblique). The correlative marker and correlative pronoun act as a demonstrative. In SRC both relative marker and correlative marker may precede the relativized element. The marking of the relativized element by relative marker or correlative marker is in complementary distribution i.e. the relativized element exists either with the correlative marker or with the relative marker. This complementary distribution is illustrated in following sentences. Sentence (11) illustrates occurrence of relativized head only with the relative marker je and sentence (12) illustrates the occurrence of relativized head with the correlative marker/pronoun.

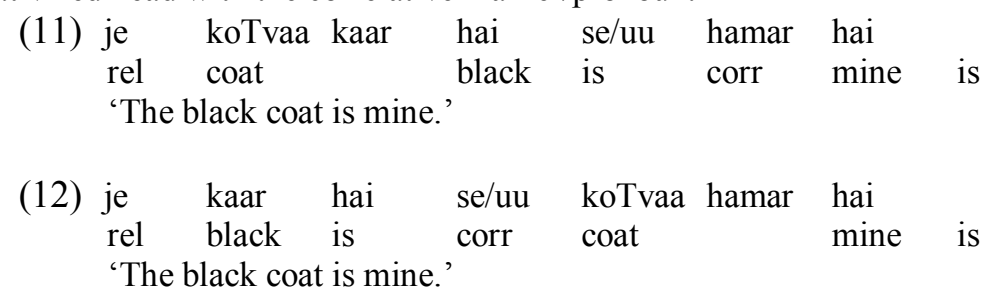

But this complementary distribution has its own limitations. As in Magahi, we have the construction that when the relative clause is left adjoined and the following clause begins with the correlative marker se, the head NP can be used with both relative marker and correlative marker as illustrated in sentence (13). At the same time when correlative pronoun is used in the left adjoined relative clauses the head can occur either with the relative marker or with the correlative pronoun, but not with both, as illustrated in the sentence (14).

$\begin{array}{lllllll}\text { (13) je koTvaa kaar hai } & \text { se } & \text { koTvaa hamar hai } & \\ \text { rel coat } & \text { black is } & \text { corr coat } & \text { mine is }\end{array}$

'The coat which is black is mine.'

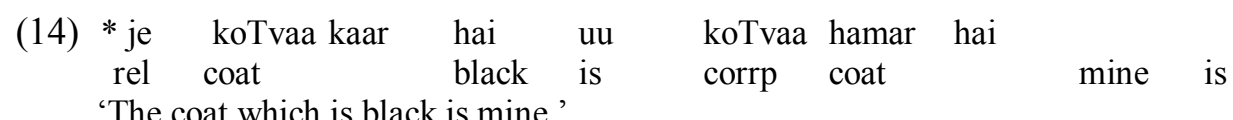

Thus, the relativized head can occur with both relative marker je and correlative marker $s e$ in the left adjoined relative clauses. However, relativized head cannot follow correlative pronoun $u$, when already used with relative marker je in a relative clause. This is illustrated in sentence (13) and (14), where the use of head NP koTvaa with both relative marker and correlative maker is acceptable but the use of head NP with both relative marker and correlative pronoun results into ungrammaticality (here I empirically contradict Chandra 2013). This is one of the remarkable differences between correlative marker se and correlative pronoun $u u$ in Magahi. Another difference is that correlative marker se cannot be used sentence initially as illustrated in sentence (15) while correlative pronoun $u u$ can be used sentence initially as illustrated in sentence (16).
(15) * se koTvaa kaar hai je hamar hai corr coat black is rel mine is

'The coat which is black is mine.'
$\begin{array}{lll}\text { (16) uu koTvaa kaar hai je } & \text { black is } \\ \text { corrp coat } & \text { blat }\end{array}$
'The coat which is black is mine.'
hamar hai
rel mine is

Because of this second difference, we find in Magahi that both correlative pronoun and correlative marker can be used together in a sentence as can be observed from following sentence (17).

$\begin{array}{lllllll}\text { uu } & \text { koTvaa } & \text { je } & \text { kaar } & \text { hai } & \text { se } & \text { hamar hai } \\ \text { corrp coat } & \text { rel } & \text { black } & \text { is } & \text { corr } & \text { mine } & \text { is } \\ \text { 'The coat which is black is mine.' } & & & & & \end{array}$

In the SRC construction in Marathi, we can have deletion or copying of relative/correlative marker, which cannot happen in Magahi. In other words, the relative marker and correlative marker in SRC in Magahi must be present as illustrated in (22). Deletion or copying of relative/correlative marker in Magahi results into ungrammaticality as illustrated in (20) and (21). Sentences (18) and (19) are illustration in Marathi, where deletion or copying of relative/correlative marker is perfectly acceptable.

Deletion of relative marker in Marathi:

$\begin{array}{lllll}\text { (18) } \varnothing & \text { itha } & \text { sikatwo } & \text { to } & \text { maanus } \\ \varnothing & \text { here } & \text { teach-pres-3sm } & \text { corr } & \text { man }\end{array}$

maadzh bhaauu aaheaa


I-poss brother

is

'The man who teaches here is my brother.'

Copying of correlative marker in Marathi:

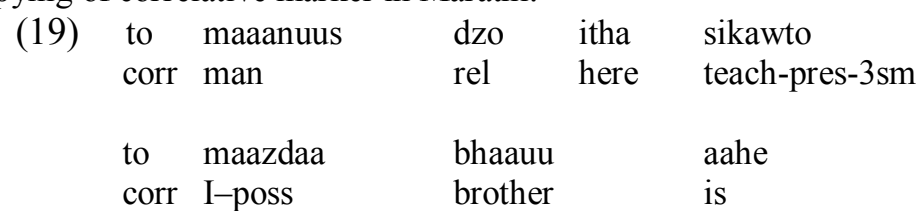

'The man who teaches here is my brother.'

(Pandharipande 1997: 79)

Deletion of relative marker in Magahi:

\begin{tabular}{|c|c|c|c|c|}
\hline (20) & $\begin{array}{l}{ }^{*} \varnothing \text { eja } \\
\varnothing \text { here }\end{array}$ & $\begin{array}{l}\text { paD }{ }^{\mathrm{h}} \text { aava } \\
\text { teaches }\end{array}$ & $\begin{array}{l}\text { hai } \\
\text { is }\end{array}$ & $\begin{array}{l}\text { se } \\
\text { CORR }\end{array}$ \\
\hline & $\begin{array}{l}\text { hamar } \\
\text { my }\end{array}$ & $\begin{array}{l}\mathrm{b}^{\mathrm{h}} \text { aaya } \\
\text { brother } \mathrm{h}\end{array}$ & & \\
\hline
\end{tabular}

Copying of correlative marker in Magahi:

(21) *se adamiyaa je eja paD aava hai

CORR man REL here teaches is

\begin{tabular}{|c|c|}
\hline $\begin{array}{l}\text { se } \\
\text { CORR }\end{array}$ & $\begin{array}{ll}\text { hamar } & \mathrm{b}^{\mathrm{h}} \text { aaya } \\
\text { my } & \text { brother is }\end{array}$ \\
\hline
\end{tabular}

'The man who teaches here is my brother.'

Presence of relative marker and correlative marker in SRC in Magahi:

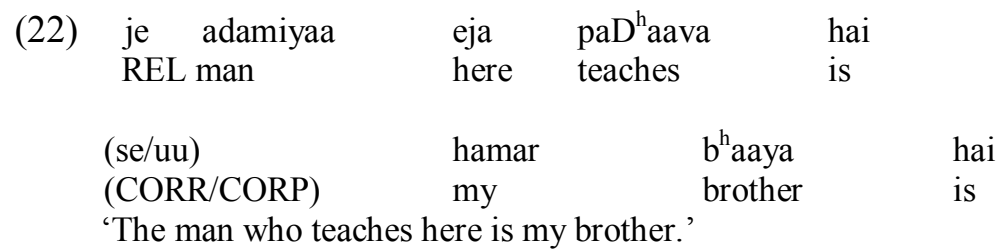

\subsection{Participial Relative Clauses}

There are three kinds of Participial Relative Clauses (PRC) in Magahi, (i) Present Participial (ii) Past Participial and (iii) Agentive Participial. Present participial in Magahi are formed by the addition of suffix -at/ ate to the verb as exemplified in the sentence (23). Past participial are formed by addition of suffix -al to the verb as in sentence (24). Finally, agentive participial are formed by the addition of suffix -valaa to the verb as in sentence (25).

(23) $\begin{array}{llll}\text { dauR-at } & \text { larkaavaa } & \text { ekaaek ruk } & \text { gelai } \\ \text { running } & \text { boy } & \text { suddenly } & \text { stop went }\end{array}$ 'The boy who was running stopped suddenly.'

(24) hamar $\begin{array}{lll}\operatorname{dek}^{\mathrm{h}}-a l & \text { ladkiaa } & \text { ukraa } \\ \text { search-PPT } & \text { girl } & \text { he-OBLQ }\end{array}$

pasand aa gelai 'He liked the girl whom I searched for him.'

$\begin{array}{lllcl}\text { panctantra } & \mathrm{paD}^{\mathrm{h}} \mathrm{e}-\mathrm{valaa} & \text { laRkaavaa } & \text { hamraa se } & \text { puchalkai...... } \\ \text { panchtantra } & \text { read-AGENT } & \text { boy } & \mathrm{me} & \text { INST ask-PST }\end{array}$

'The boy who was reading Panchtantra, asked me.....'

\subsection{Restrictive and Non-Restrictive Relative Clauses}


Yadav (1996) writes about the restrictive and non-restrictive relative clauses "those that restrict the potential referent of the noun phrase are restrictive relative clause, and those that provide an additional piece of information about the noun phrase referent which is already fully specified are non-restrictive relative clauses." Like Marathi and Punjabi, SRC is usually restrictive in Magahi. PRC is ambiguous between restrictive and nonrestrictive. But when there is a proper noun as head in both SRC and PRC, it is non-restrictive. This is also true for Marathi and Punjabi.

Following sentence (26) is an illustration of SRC as restrictive clause in Magahi:

(26) je koTval kaar hai $\begin{array}{lllll}\text { se } & \text { koTvaa hamar hai } & & \\ \text { rel coat } & \text { black is } & \text { corr } & \text { coat }\end{array}$
'The coat which is black is mine.'

Following sentence (27) is an illustration of SRC as a non-restrictive clause in Magahi:

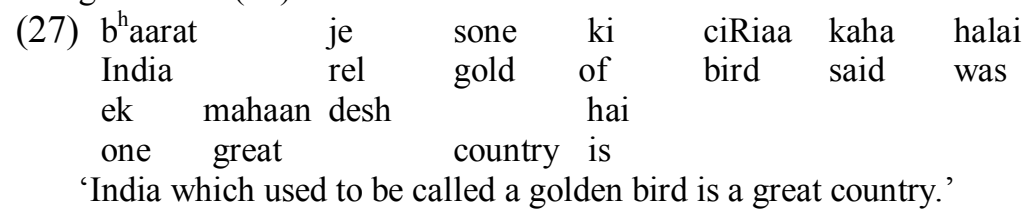

Following sentence (28) is an illustration of SRC with restrictive interpretation in Marathi:

(28) $\begin{aligned} & \text { dzo } \\ & \text { rel }\end{aligned}$
$\begin{aligned} & \text { boy } \\ & \text { uttam }\end{aligned}$
$\begin{aligned} & \text { tSitrakaar kaal } \\ & \text { 'The boy who had come yesterday is an excellent painter.' }\end{aligned}$

(Pandharipande 1997:81)

Following sentence (29) is an illustration of SRC with non-restrictive interpretation in Marathi:

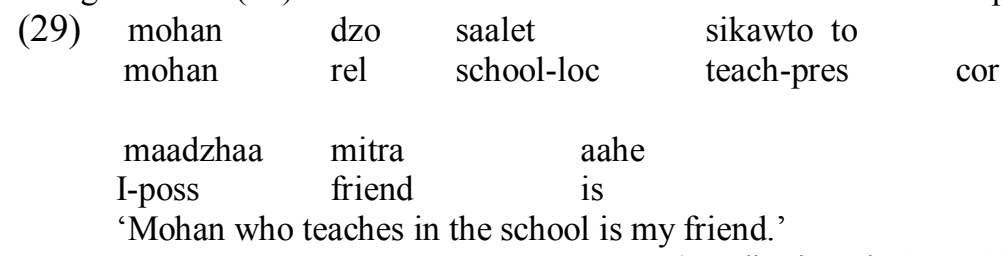

(Pandharipande 1997:81-82)

Non-restrictive relative clause has a strict word-order. It must be embedded in the main clause. Also they do not allow the presence of correlative marker. PRC is ambiguous between restrictive and Non-restrictive reading as the word order of PRC is strict. The restrictive reading of PRC in Magahi is illustrated in following sentence (30).

$\begin{array}{lllll}\text { dauR-at } & \text { larkaavaa } & \text { ekaaek } & \text { ruk } & \text { gelai } \\ \text { running } & \text { boy } & \text { suddenly } & \text { stop } & \text { went }\end{array}$

PRC in Marathi which is ambiguous between restrictive and non-restrictive reading is illustrated in following sentence (31).
(31)
paluun gelelaa
mulgaa
run-conj.part go-perf.part boy
'The boy who had run away was found.'

(Pandharipande 1997: 80)

PRC in Marathi with proper noun which has non-restrictive reading is illustrated in following sentence (32).

$\begin{array}{llll}\text { (32) naagpurlaa } & \begin{array}{l}\text { raahnaaraa } \\ \text { live-pres }\end{array} & \begin{array}{l}\text { maadzhaa } \\ \text { I-poss }\end{array} & \begin{array}{l}\text { bhaauu } \\ \text { brother }\end{array} \\ \text { dilip wakiil } & \text { aahe } & \\ \text { dilip lawer } & \text { is } & \end{array}$


'My brother Dilip who lives in Nagpur is a lawer.'

(Pandharipande 1997: 81)

PRC in Magahi, with proper noun is generally considered as having non-restrictive reading as illustrated in the following sentence (33).

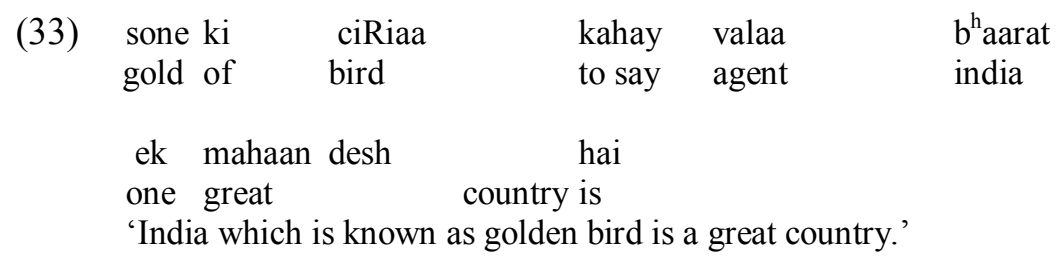

PRC in Punjabi with proper noun having non-restrictive reading is illustrated in following sentence (34).

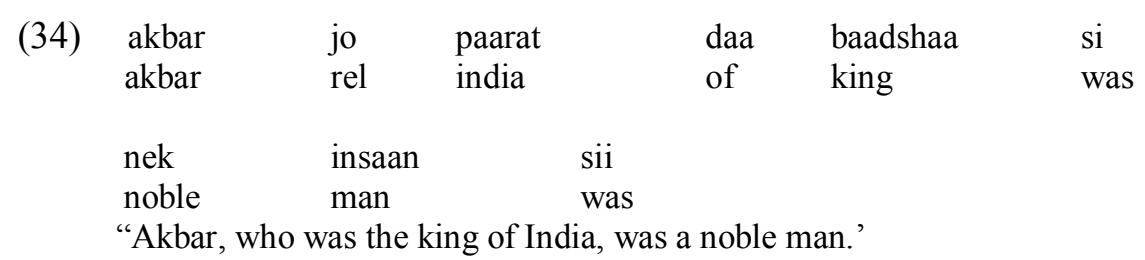

(Bhatia 1993: 55)

PRC in Punjabi without proper noun and has restrictive relative clause interpretation is illustrated in sentence (35).

\begin{tabular}{|c|c|c|c|c|}
\hline$(35)$ & $\begin{array}{l}\text { nayuu } \\
\text { new }\end{array}$ & $\begin{array}{l}\text { yaark } \\
\text { york }\end{array}$ & $\begin{array}{l}\text { vicc } \\
\text { in }\end{array}$ & $\begin{array}{l}\text { rain } \\
\text { live }\end{array}$ \\
\hline & $\begin{array}{l}\text { muNdaa } \\
\text { boy }\end{array}$ & $\begin{array}{l}\text { meraa } \\
\text { my }\end{array}$ & $\begin{array}{l}\text { dost } \\
\text { friend }\end{array}$ & $\begin{array}{l}\text { ai } \\
\text { is }\end{array}$ \\
\hline
\end{tabular}

\subsection{Position of Head Noun}

'The boy who lives in New York is my friend.'

(Bhatia 1993: 56)

Head noun may be present in matrix clause (as illustrated in sentence 12) or in correlative clause (as illustrated in sentence 11) or in both the clauses (as illustrated in sentence 13). Non-restrictive finite clauses immediately follow the head noun (as illustrated in sentence 25) and participial relative clauses precede the head noun (as illustrated in sentences 23, 24 and 25). However in Marathi participial relative clauses generally precede the head noun when they are non-restrictive and follow it when they are restrictive (Pandharipande 1997).

\subsection{Position of Relativized Element}

Change in the position of relativized element brings about a change in the focus on that element. This is true for both Marathi and Punjabi. Following sentences (36) and (37) in Magahi illustrates this.

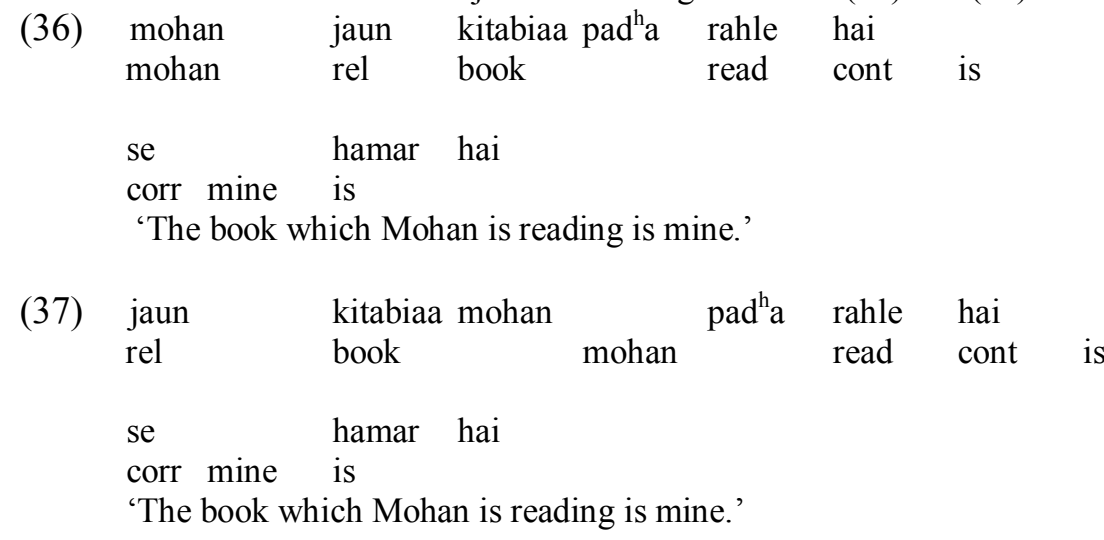


In the above sentences (36) and (37), kitabiaa is object. In sentence (37) focus is on kitabiaa which is a result of fronting of the relativized element.

\subsection{Headless Relative Clause}

As in other Indo-Aryan languages, like Marathi and Punjabi, Magahi also shows the formation of Headless Relative clauses. This is shown in the following sentence (38).

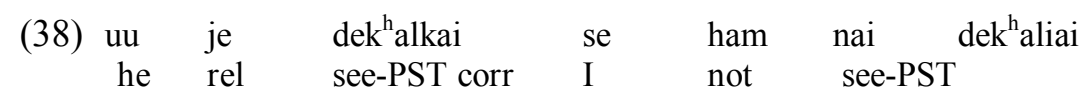

'I couldn't see what he saw.'

In the above sentence (38) we do not have presence of a head either after relative marker je or after correlative marker se. So, illustration (38) is an example of headless relative clause in Magahi. We find this kind of headless relative clauses in both Marathi and Punjabi. In addition to this Marathi has one more kind of headless clause formation in the form of PRC 'where the assumed head NP is generic' (Pandharipande 1997). This is illustrated in sentence (39).
(39) saaNkaTaat
calamity-loc
madat
help
karNaaraa
do-pres.part
(maanuus)
(person)

kharaa mitra asto
true friend is
'The person who helps in the time of calamity is a true friend.'

\subsection{Noun Phrases That Can Be Relativized}

All subject, object and indirect object can be relativized. Sentence (40) is an example for the relativization of subject. Sentence (41) is an example for relativization of object and sentence (42) shows the relativization of indirect object.

$\begin{array}{llllll}\text { (40) } & \text { je laRkaawaa lambaa } & \text { hai } & \text { se hamar } & \mathrm{b}^{\mathrm{h}} \text { aaya hai } \\ \text { rel boy } & \text { tall } & \text { is } & \text { corr my } & \text { brother is }\end{array}$ 'The boy who is tall is my brother.'

(41) rohit ke kinalkaa kitabiaa cuhavaa kutar delkai rohit by purchased book rat cut did

'The rat destroyed the book purchased by Rohit.'

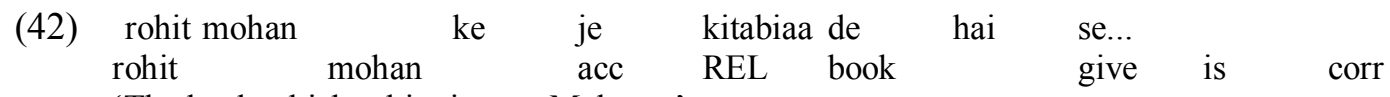
'The book which rohit gives to Mohan...'

Like Marathi, in Magahi too, both possessor and possessed noun phrases can be relativized by using the sentential relative clause as illustrated in following sentences (43) and (44).

Relativization of possessor NP (SRC) in Magahi:

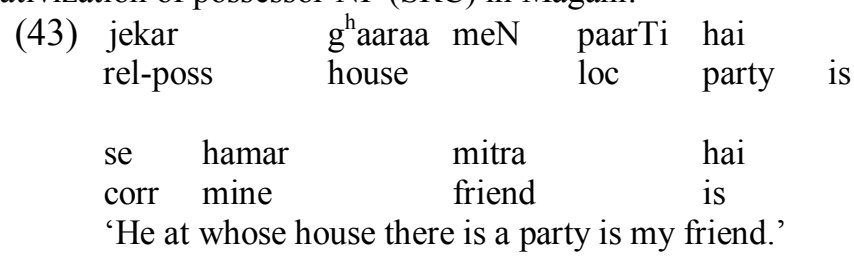

Relativization of possessed NP (SRC) in Magahi:
(44) okar
je bahiniaa
he-poss
rel sister
paTnaa meN rah hai
patna loc live is

$\begin{array}{rlll}\text { se } & \text { hamar } & \text { mitra } & \text { hai } \\ \text { corr } & \text { mine } & \text { friend } & \text { is }\end{array}$
'The sister of his who lives in Patna is my friend.'

In Magahi, relativization of possessor NP using PRC is not possible while it can be in Marathi. However, in Marathi, relativization of possessor which is alienable from the possession cannot happen using the strategy of PRC as illustrated in (45). On the other hand, when possession is inalienable from the possessor, relativization 
of possessor by using the strategy of participial relative is readily acceptable (Pandharipande 1997) as illustrated in (46).

$\begin{array}{llll}\text { (45) } ? /{ }^{*} \mathrm{~g}^{\mathrm{h}} \text { araat } & \text { puskal } & \text { maansa asnaaraa } & \text { mulgaa } \\ \text { house-loc } & \text { many } & \text { people } & \text { is boy }\end{array}$

'The boy in whose house there are many people.'

(46) sariraat taakad aslelaa mulgaa

body-loc strength is boy

'The boy who has strength in (his) body.'

(Pandharipande 1997:98)

\subsection{Multi-head Correlatives}

In Magahi, the relative marker can occur more than once whereas correlative marker occurs only once.
jekaraa
je
kare ke
man kailakai se
kailkai
rel-oblq rel do of
desire occurred
corr did

'Whatever one desired to do, one did.'

We observe from the above example that relative marker is used twice i.e. jekaraa and je while the correlative marker is used just once i.e. se. We find that in Marathi the frequency of correlative marker is equal to the frequency of relative marker. This is illustarted in (44) where there are two relative markers je and jaisi and also two correlative markers taiseci and tyaa.

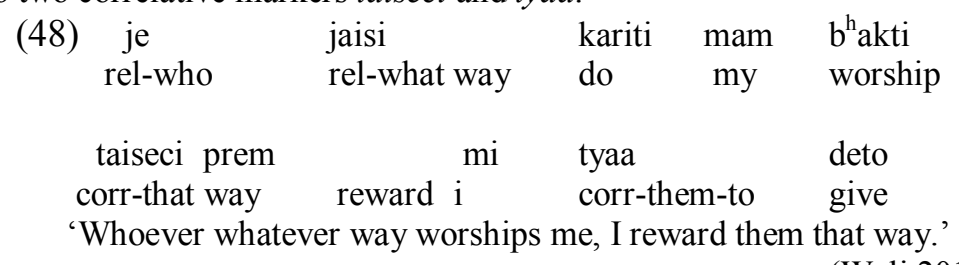

\section{Conclusions}

(Wali 2011: 266)

In this paper there is a description of syntax of relative clause formation in Magahi based on Comrie and Smith (1977). There is also a comparison of relative clause forming strategy in Magahi with that of three Indo-Aryan languages: Marathi, Punjabi and Maithili. Typologically, the relative clause forming strategies in these languages are similar, with some differences. In Magahi, oblique form of relative marker is used when a case marker follows a lexeme. Marathi has freedom of deletion or copying of relative marker and correlative marker which is not possible in Magahi. The interpretation of SRC and PRC as restrictive and non-restrictive relative clauses is almost similar in the languages considered here. Magahi also has unique features of relative clause. The uniqueness of relative clause in Magahi is the presence of a correlative pronoun $u u$ along with correlative marker $s e$. These correlatives occur in complementary distribution. They can be used together in the same sentence but in different positions. Like Marathi and Punjabi, even Magahi has presence of headless relative clause in it. In the formation of multi-head correlatives in Magahi more than one relative marker occur while correlative markers occur only once, while in Marathi, the frequency of relative marker and correlative marker is same.

[1]. Bhatia, Tej. 1993. Punjabi. London: Routeledge.

\section{References}

[2]. Bhatt, Rajesh. 2003. "Locality in correlatives". Natural Language and Linguistic Theory 210: 485-541. Netherland: Kluwer Academic Publishers.

[3]. Chandra, Shweta. 2013. "Relative clauses in Magahi". Nepalese Linguistics 28: 15-24.

[4]. Comrie, Bernard; and Smith, Norval. 1977. "Lingua Descriptive Series: Questionnaire”. Lingua 42.1: 1-71. Special issue.

[5]. Pandharipande, Rajeshwari.V. 1997. Marathi. London: Routeledge.

[6]. Riemsdijk, Van, H. 2006. "Free relatives". In: Martin, Everaert and Riemsdijk Van, H (eds.), The Blackwell Companion to Syntax, vol.II. Oxford: Blackwell. 338-382.

[7]. Subbarao, Karumuri, V. 2012. South Asian Languages: A Syntactic Typology. Cambridge: Cambridge University Press.

[8]. Wali, Kashi. 2011. "Correlatives comparatively: Sanskrit vs. Marathi”. Indian Linguistics 72: 257-274. Pune: Linguistic Society of India.

[9]. Yadav, Ramawatar. 1996. A Reference Grammar of Maithili. Berlin: Mouton De Gruyter.

\footnotetext{
${ }^{\mathrm{i}}$ We are grateful to Professor K V Subbarao for his comments on this article.
} 